\title{
A framework to select commercial bank partner using fuzzy BSC-DEA method
}

\author{
Moussa Azarbad ${ }^{a^{*}}$, Mostafa Ekhtiari ${ }^{\mathrm{b}}$, Amir Homayoun Sarfaraz ${ }^{\mathrm{a}}$ and Farshid Abdi ${ }^{\mathrm{a}}$
}

${ }^{a}$ Department of Industrial Engineering, Islamic Azad University, South Tehran Branch, Tehran, Iran

${ }^{b}$ Department of Industrial and Mechanical Engineering, Islamic Azad University, Qazvin Branch, Qazvin, Iran

\begin{tabular}{l}
\hline A R T I C L E I N F O \\
\hline Article history: \\
Received March 29, 2011 \\
Received in Revised form \\
June, 15, 2011 \\
Accepted 15 June 2011 \\
Available online \\
17 June 2011 \\
\hline Keywords: \\
Data envelopment analysis \\
Balanced score card \\
Efficiency \\
Banking industry \\
Market alliance
\end{tabular}
A B S T R A C T

\begin{abstract}
One of the primary concerns of many corporate organizations is to assess the weakness and strength of their future partners in an attempt to reduce all potential risks involved with them. In this paper, we present a BSC-DEA based model to indentify strengths, weaknesses, opportunities and threats of a firm. The proposed model of this paper assumes there are various uncertainties associated with all input/output parameters and uses fuzzy numbers to handle the uncertainties. We also consider a real-world case study of banking industry where four major banks are possible candidates of a partnership and implement the proposed model of this paper for this case study. The results of this study reveal some of the issues such as weakness of electronic banking, services and resource allocation as part of their infrastructure problems.
\end{abstract}

(C) 2011 Growing Science Ltd. All rights reserved.

\section{Introduction}

A strategic alliance is formed by at least two business partners, which set long term relationship for achieving common goals to remain legally independent, to share management controls and interests in performance and allocated responsibilities, and finally to continue cooperation in one of some strategic fields such as technology, product and service. In recent years, there is an increasing interest among many corporations in having strategic alliances (Wu et al., 2009). One of the primary concerns in such firms is to setup an appropriate strategy on choosing the right partners to reduce any possible risk. Brendel (1951) is believed to be the first who emphasized on the importance of strategy for choosing appropriate partners by considering 20 factors in a real-world case study of distribution network. Pegram (1965) performed more expanded studies about strategic partner selection. He presented some criteria for evaluating business partners in several categories such as credit and financial conditions, production line, reputation and popularity, sales performance and power, management capability, management altitude, and size of members in distribution network.

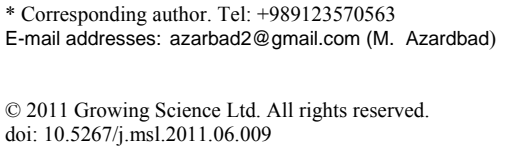


Overby (2005) explained that companies could benefit of advantages of own business partners in specific periods. He also showed that selecting a business partner has dynamic nature and it depends on strength or weakness of partner, which changes from one period to another. Dong and Glaister (2006) presented 20 main factors for business partners selection in Chinese companies. The factors include resources and raw material, man power, executive ability, domestic market recognition, environmental factors recognition, familiarity with partners' culture, product, distribution network, seller and provider recognition, reputation and management. Bierly and Gallagher (2007) explained that applying a multi level set, which includes three main factors of strategic coordination, trust and expediential strategy. Wu et al. (2009) summarized main factors in selection of business partners in five areas including business partner specification, coordination and compatibility degree, invisible properties, capabilities and marketing knowledge and complementary capabilities. Holmberg and Cummings (2009) presented a dynamic tool for business partner selection for target market (industry) evaluation and distinct companies, which was useful for polygon alliances and different industrial fields.

During the past few years, there have been different quantitative and qualitative decisions making models for selecting business partner in strategic alliances. It could be pointed some done researches. Mikhaliov (2002) used fuzzy analytical network process (FANP) for business partner selection in virtual firms. Jarimo (2006) developed a mixed integer linear programming model to form virtual firms. A decision support system (DSS) and its related software was designed and presented by Hacklin et al. (2006). The proposed DSS has been made for selecting business partner in strategic alliances.

Yang et al. (2007) used analytical hierarchy process (AHP) for outsourcing process in business level, so they used 20 main factors in three basic areas of risk, expectations and environmental conditions. Eden (2007) presented a model for selecting business partner in research and development, upon hypothesis test and its related statistical analysis using a quantitative research method. Wu et al. (2009) selected important and effective criteria to select business partner by applying analytical network process. Doherty (2009) suggested a qualitative method upon which effective key factors for selection of business partners were presendted forinternational franchise.

Surveys in economic and banking affairs in developed countries show that making a strategic alliance in banking can improve banking. So the reasons can cause the strategic alliance are as follow:

- Lack of suitable software packages to perform online banking,

- Reliance on paperwork in banking system,

- Time wasted of customers for bank services,

- Limitation of exchanging on large amount of money between different bank accounts,

- Low speed of internet lines,

- Lack of suitable communication lines for using POS and remote services,

- Limitation on daily receiving money from ATM,

- Bureaucracy in the body of organization,

- Increasing in income and profitability.

In this paper, we present an integrated balanced score card (BSC) and data envelopment analysis (DEA) to measure the relative efficiencies of different units of banks based on some financial and non-financial figures. The proposed model of this paper is implemented for some private Iranian banks called Saman bank. In this study, we try to find appropriate solutions for eliminating some 
critical factors, which make an organization inefficient such as increasing income and profitability, deleting limitation on exchanging lots of money between banks, bureaucracy and increasing receiving speed in services. The organization of this paper is as follows. We first introduce some basic elements of BSC and DEA in sections 2 and 3, respectively. The proposed model of this paper in descriptive steps is given in Section 4. Section 5 is devoted for the implementation of the proposed model and the concluding remarks are given in the last section to summarize the contribution of the paper.

\section{Balance score card}

Balance score card (BSC) model was first introduced by Kaplan and Norton (1992), which creates a balanced framework between financial and other nonfinancial units of organizations. BSC creates a cause and effect interaction model between managers and staff and it watches the organization based on four perspectives as follow: financial, customer, internal business processes, learning and maturity.

Financial perspective links the organization to its shareholders with main attention to the question: "How do we look to our shareholders and those with a financial interest in the organization?". Customer perspective concentrates on identifying customers and some ways to meet their needs. In internal business processes perspective, some processes are developed by organization to create value for customers and stockholders effectively and efficiently. Learning and maturity perspective identifies the infrastructure that the organization must build to create long-term growth and improvement (Asosheh et al., 2010).

Success in processes for an organization depends not only to fast and on time information, but also it depends on staff's ability and information system improvement. Improving internal processes, staff's capabilities will eventually lead an organization to perform well in terms of financial figures. BSC ability in designing performance evaluation indices has raised researches to use this technique as a tool for designing indices. Increasing use of BSC framework in many recent researches and various management field like SCM (Bhagwat \& Sharma, 2007), R\&D project (Eilat et al., 2008), ecommerce (Hasan \& Tibbits, 2000; Rickards, 2007), ERP (Chand et al., 2005) and e-business (Bremser \& Chung, 2005) have several reasons. First, compared with traditional measurement systems that only include financial measures the BSC is designed to improve managers' decisionmaking by guiding their attention to a broader vision of the company's operations (Kaplan \& Norton, 1992; Rickards, 2007; Wong-On-Wing et al., 2007; Maltz et al., 2003). Second, as a holistic performance measurement system, the BSC provides causal links connecting the multiple classes of non-financial measures ("drivers of the performance") and the financial measures ("final outcome") (Campbell et al., 2002; Ittner et al., 2003; Bhagwat \& Sharma, 2007; Wong-On-Wing et al., 2007).

We should know that BSC suggests no way to reach the goal, therefore in order to find improvement way for organization we must use another techniques, and also consider that this model is not prepared for evaluation performance of an organization for several years or comparison of performance among other same organizations. This weakness could be removed by data envelop analysis.

\section{Data envelopment analysis}

Data envelopment analysis (DEA) is a non-parametric one with mathematical approach, which evaluates the performance of decision-making units based on some inputs and outputs. Charnes et al. (1978) is believed to be the first who presented this technique. In DEA technique, the considered entity, which converts inputs to outputs is called decision making units (DMU). DMUs may be a hospital, bank, or store and something like these; in defining the DM units, decision maker (DM) 
units must have equal inputs and outputs. In DEA technique, the organization outputs are measured upon its known inputs, whereas this technique is able to compare performance of an organization during several years or to compare the performance of an organization to others. Despite the other nonparametric techniques, this technique does not need estimation of production function and only depends on inputs and outputs values for each DMU and measure the relative efficiency of each unit based on the other units.

DEA technique is applicable by different models which CCR (Charnes et al., 1978) is one of the most useful one. In CCR model, first is allocated a mark for efficiency to every unit, units with mark 1, are known as efficient units. In this model, with assumption of constant output to scale, by efficiency calculation, the optimum coefficient of inputs and outputs of each unit is obtained so that efficiency is ratio of sum of weighted values of outputs to sum of weighted values of inputs.

It should be considered that DEA technique does not play any role in defining input and output indices although it is very powerful in comparison of performance and give improvement solution. Therefore it seems that it would be possible to use combination of this technique and BSC model either for evaluation of strategic indices of an organization in a length trend and as an approach to solve the business partner selection problem.

Combination of BSC and DEA opens the door to measuring the performance of an organization and defining the improvement way, so that defined criteria are classified into two input and output categories by BSC, then by using the DEA is used to compare different units. In this article, criteria associated with one of the Iranian banks are presented to select business partner and ranking the considered alternatives will be performed using a proposed model from combining BSC and DEA. In the next section, an algorithm proposed is presented for solving the business partner selection problem in bank.

\section{Proposed algorithm}

Algorithm proposed for business partner selection in bank is presented as follows:

\subsection{First step: Defining business partner selection criteria by using BSC and Delphi methods}

One of the important matters in business partner selection problem is to define criteria and sub criteria. Therefore, in this article, the BSC and Delphi method are used as follow:

\subsubsection{BSC model}

To define criteria and sub criteria, BSC model is used. One of the advantages of this model is compatibility between criteria and short/long-term objectives of a bank, because BSC is of the useful tools for achieving the goals and strategies of bank according to four perspectives including financial, customer, internal business processes, and learning and maturity (Quezada et al., 2009). In addition, there are three main reasons for creation and development of BSC model, which are as follow,

- creating and maintaining useful and effective relationships,

- receiving a good output for an organization,

- establishing balance and improvement among criteria

BSC in late of 1980's and early of 1990's raised as a method for helping the organization in complicated and polygon environments. During the recent years, BSC implementation has increased as a framework for revolution management in organization. Fig. 1 shows the breakdown structure for defined criteria of a bank in four perspectives of BSC: 


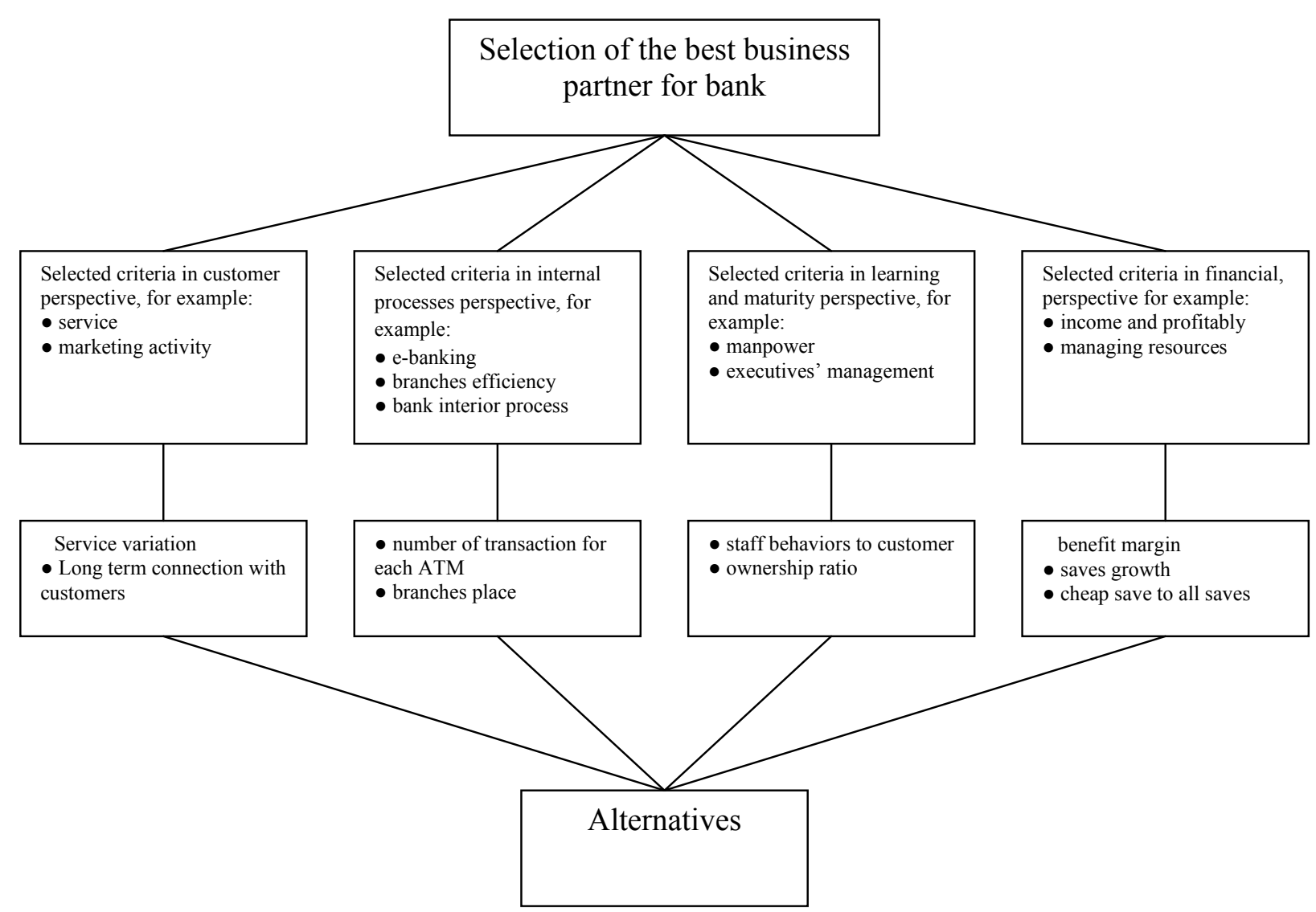

Fig. 1. Criteria, sub criteria and alternatives to select the best business partner for a bank

\subsubsection{Delphi method}

In this step, the output of BSC is used for selection problem. Delphi uses DMs judgment information, in this work includes managers and experts of banking bases. According to this method, first, an interview is performed with all experts individually about the BSC outputs. Then by considering their points, interviews will be repeated again and finally we gather all figures and points, define final criteria, and sub criteria.

\subsection{Second step: Constructing fuzzy decision matrix compatible to BSC model}

In this step, available alternatives are presented for creating a strategic alliance. The aim is that one of them to be selected according to criteria and sub criteria defined in first step. Table 1 shows a decision matrix compatible to BSC perspectives under uncertainty conditions.

\section{Table 1}

Decision matrix compatible to BSC areas under uncertainty conditions

\begin{tabular}{|c|c|c|c|c|c|c|c|c|c|c|c|c|}
\hline & \multicolumn{2}{|c|}{$\begin{array}{l}\text { Customer } \\
\text { perspective }\end{array}$} & \multirow[b]{2}{*}{$C_{t}$} & \multicolumn{3}{|c|}{$\begin{array}{l}\text { Internal processes } \\
\text { perspective }\end{array}$} & \multicolumn{3}{|c|}{$\begin{array}{l}\text { Learning and maturity } \\
\text { perspective }\end{array}$} & \multicolumn{2}{|c|}{$\begin{array}{l}\text { Financial } \\
\text { Perspective }\end{array}$} & \multirow[b]{2}{*}{$C_{n}$} \\
\hline & $C_{1}$ & $\ldots$ & & $C_{t+1}$ & $\ldots$ & $C_{p}$ & $C_{p+1}$ & $\ldots$ & $C_{q}$ & $C_{q+1}$ & $\ldots$ & \\
\hline$\overline{A_{1}}$ & $\tilde{a}_{11}$ & $\ldots$ & $\tilde{a}_{1 t}$ & $\tilde{a}_{1(t+1)}$ & $\ldots$ & $\tilde{a}_{1 p}$ & $\tilde{a}_{1(p+1)}$ & $\ldots$ & $\tilde{a}_{1 q}$ & $\tilde{a}_{1(q+1)}$ & $\ldots$ & $\tilde{a}_{1 n}$ \\
\hline$\vdots$ & $\vdots$ & $\because$ & $\vdots$ & $\vdots$ & $\because$ & $\vdots$ & $\vdots$ & $\because$ & $\vdots$ & $\vdots$ & $\because$ & $\vdots$ \\
\hline$A_{m}$ & $\tilde{a}_{m 1}$ & $\ldots$ & $\tilde{a}_{m t}$ & $\tilde{a}_{m(t+1)}$ & $\ldots$ & $\tilde{a}_{m p}$ & $\tilde{a}_{m(p+1)}$ & $\ldots$ & $\tilde{a}_{m q}$ & $\tilde{a}_{m(q+1)}$ & $\ldots$ & $\tilde{a}_{m n}$ \\
\hline
\end{tabular}


In Table 1:

$A_{i}=$ Alternative $i($ for $i=1, \ldots \ldots, m)$ for business partner selection,

$\left(C_{1}, \ldots, C_{t}\right)=$ defined criteria in customer perspective,

$\left(C_{t+1}, \ldots, C_{p}\right)=$ defined criteria in internal processes perspective,

$\left(C_{p+1}, \ldots, C_{q}\right)=$ defined criteria in learning and maturity perspective,

$\left(C_{q+1}, \ldots, C_{n}\right)=$ defined criteria in financial perspective,

$\tilde{a}_{\mathrm{ij}}=$ allocated fuzzy value to alternative $i($ for $i=1, \ldots, m)$ by considering criterion $j$ (for $j=1, \ldots, n$ ).

\subsubsection{Fuzzy theory}

In a decision making process, often DMs are coming across some uncertainties and hesitation. In other words, natural language for describing comprehension and judgment in mental way is uncertain and ambiguous. In order to get rid of this ambiguity, fuzzy sets theory (Zadeh, 1965) has been presented to describe linguistic expressions through decision-making process. In the following, for the purpose of reference, some important definitions and notations of fuzzy sets theory from (Kaufmann \& Gupta, 1991; Dubois \& Prade, 1980; Tsao, 2009) are reviewed.

Let $X$ be the universe of discourse, $X=\left\{x_{1}, \ldots, x_{n}\right\}$. A fuzzy set $\tilde{A}$ of $X$ is a set of order pairs, $\left\{\left(x_{1}, \mu_{\tilde{A}}\left(x_{1}\right), \ldots,\left\{\left(x_{n}, \mu_{\tilde{A}}\left(x_{n}\right)\right\} . \mu_{\tilde{A}}: X \rightarrow[0,1]\right.\right.\right.$ is the membership function of $\tilde{A}$, and $\mu_{\tilde{A}}\left(x_{i}\right)$ stands for the membership degree of $x_{i}$ in $\tilde{A}$ and as $\mu_{\tilde{A}}$ tends to 1 , the degree increases.

The height of a fuzzy set is the largest membership grade attained by any element in that set. A fuzzy set $\tilde{A}$ in the universe of discourse $X$ is called normalized when the height of $\tilde{A}$ is equal to 1 . A fuzzy number is a fuzzy subset in the universe of discourse $X$ that is both convex and normal.

Fuzzy membership function has more types. This paper adopts the type of a triangular fuzzy number. A positive triangular fuzzy number can be defined as $\tilde{A}=\left(a^{l}, a^{m}, a^{r}\right)$, shown in Fig. 2.

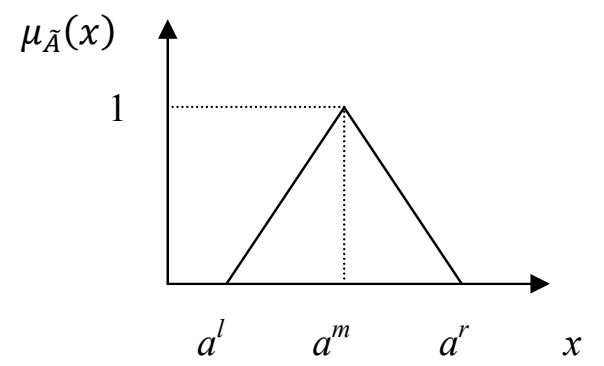

Fig. 2. Triangular fuzzy number $\tilde{A}$.

The membership function is defined as:

$\mu_{\tilde{A}}(x)=\left\{\begin{array}{cc}\frac{x-a^{l}}{a^{m}-a^{l}}, & a^{l} \leq x \leq a^{m} \\ \frac{x-a^{r}}{a^{m}-a^{r}}, & a^{m} \leq x \leq a^{r} \\ 0, & \text { otherwise. }\end{array}\right.$ 
By the extension principle, the fuzzy sum $(+)$ and fuzzy subtraction $(-)$ of any two triangular fuzzy numbers are also triangular fuzzy numbers; but the multiplication $(\times)$ of any two triangular fuzzy numbers is only an approximate triangular fuzzy number. Given any two positive triangular fuzzy numbers, $\tilde{A}=\left(a^{l}, a^{m}, a^{r}\right)$ and $\tilde{B}=\left(b^{l}, b^{m}, b^{r}\right)$, some main operations of fuzzy numbers $\tilde{A}$ and $\tilde{B}$ can be expressed as follows:

$\tilde{A}(+) \tilde{B}=\left[a^{l}+b^{l}, a^{m}+b^{m}, a^{r}+b^{r}\right]$

$\tilde{A}(-) \tilde{B}=\left[a^{l}-b^{l}, a^{m}-b^{m}, a^{r}-b^{r}\right]$,

$\tilde{A}(\times) \tilde{B} \cong\left[a^{l} b^{l}, a^{m} b^{m}, a^{r} b^{r}\right]$,

$\tilde{A}=\left(a^{l}=\min _{k}\left\{a_{k}^{l}\right\}, a^{m}=\frac{\sum_{k=1}^{K} a_{k}^{m}}{K}, a^{r}=\max _{k}\left\{a_{k}^{r}\right\}\right)$,

where $K$ is number of $\mathrm{DM}(\mathrm{s})$.

Consider a fuzzy programming problem with triangular fuzzy coefficients as follows,

$\max \sum_{j=1}^{n}\left(C_{j}^{l}, C_{j}^{m}, C_{j}^{r}\right) x_{j}$

subject to

$\sum_{j=1}^{n}\left(a_{j}^{l}, a_{j}^{m}, a_{j}^{r}\right) x_{j} \geq\left(b^{l}, b^{m}, b^{r}\right)$,

$x_{j} \geq 0$,

The crisp model of this problem is as follows, (Jiménez et al., 2007):

$\max \sum_{j=1}^{n} C_{j}^{m} x_{j}$

subject to

$\sum_{j=1}^{n}\left(\alpha\left(\frac{a_{j}^{l}+a_{j}^{m}}{2}\right)+(1-\alpha)\left(\frac{a_{j}^{r}+a_{j}^{m}}{2}\right)\right) x_{j} \geq \alpha\left(\frac{b^{m}+b^{r}}{2}\right)+(1-\alpha)\left(\frac{b^{l}+b^{m}}{2}\right)$,

$x_{j} \geq 0, \alpha \in[0,1]$.

4.3 Three step: Combining CCR model with fuzzy theory

The CCR model admits both input-oriented and output-oriented models. While the input-oriented model focuses on savings of inputs, the output-oriented model concentrates on enhancement of outputs.

\subsubsection{The CCR}

The CCR model defines the relative efficiency of a specific unit $P_{0}$ as the ratio between the sum of its weighted outputs $\sum_{r} u_{r} y_{r_{o}}$ and the sum of its weighted inputs $\sum_{i} v_{i} x_{i_{o}}$. We assume that $x_{i j}>0$ and $y_{i j}$ $>0$. The weights, $u_{r}>0$ and $v_{i}>0$, are defined in a way that allows the bank in question to present itself in the most favorable way. The ratio, which is to be maximized for unit $P_{0}$, leads to the following objective function:

$\max _{u, v} s_{o}=\frac{\sum_{r} u_{r} y_{r_{o}}}{\sum_{i} v_{i} x_{i_{o}}}$

The optimization problem in Eq. (8) is unbounded. Normalization constraints (one for each unit) force the ratios of weighted outputs to weighted inputs of every unit to be less than or equal to 1 , as shown below:

$\frac{\sum_{r} u_{r} y_{r j}}{\sum_{i} v_{i} x_{i j}} \leq 1, \forall j$ 
The constrained optimization problem defined by Eq. (8) and Eq. (9), including the positivity constraints of the weights, construct the original CCR model in its ratio form. The ratio formulation was transformed in (Charnes et al., 1978) into an equivalent linear programming formulation known as the input-oriented CCR model shown in given in Eq. (10):

$\max { }_{u, v} s_{o}=\sum_{r} u_{r} y_{r_{o}}$

subject to

$\sum_{i} v_{i} x_{i_{o}}=1$,

$\sum_{r} u_{r} y_{r j}-\sum_{i} v_{i} x_{i j} \leq 0, \quad \forall j$

$x_{i j}, y_{r j} \geq 0 \quad \forall r, i, j$,

$u_{r} \geq 0 \quad \forall r$

$v_{i} \geq 0 \quad \forall i$.

In this formulation, no a priori values are assigned to the input-output weights. This means, for example, that an alternative, which is a superior producer of a marginally important output, might be diagnosed as efficient even if it performs poorly with respect to all other outputs. Furthermore, in evaluating different alternatives, the same factors may be assigned widely different weights for the same dimension. Hence, the scores provided by the CCR model are not necessarily good indicators for partner selection, as they might not reflect the desired balance among the outputs of the model.

\subsubsection{BSC-CCR model}

The single-level BSC-CCR linear formulation is represented by Eq. (11). In this formulation, the balancing constraints are divided into two groups-lower-and upper-bound constraints, for each output card $O_{k}, k=1, \ldots, K_{O}$, and input card $I_{k}, k=1, \ldots, K_{I}$. The lower and upper bounds are denoted $\left[L_{O_{k}}, U_{O_{k}}\right]$ and $\left[L_{I_{k}}, U_{I_{k}}\right]$ for the outputs and inputs, respectively. These constraints ensure that any score produced by the model reflects the desired balance among the output cards and among the input cards.

$\max { }_{u, v} z_{o}=\sum_{r} u_{r} y_{r_{o}}$

subject to

$\sum_{i} v_{i} x_{i_{o}}=1$,

$\sum_{r} u_{r} y_{r j}-\sum_{i} v_{i} x_{i j} \leq 0, \forall j$

$-\sum_{r \in o_{k}} u_{r} y_{r o}+L_{o_{k}} \sum_{r} u_{r} y_{r o} \leq 0, \quad \forall k=1, \ldots, K_{O}$,

$\sum_{r \in o_{k}} u_{r} y_{r o}-U_{o_{k}} \sum_{r} u_{r} y_{r o} \leq 0, \quad \forall k=1, \ldots, K_{O}$,

$-\sum_{i \epsilon I_{k}} v_{i} x_{i o}+L_{I_{k}} \sum_{i} v_{i} x_{i o} \leq 0, \quad \forall k=1, \ldots, K_{I}$,

$\sum_{i \in I_{k}} v_{i} x_{i o}-U_{I_{k}} \sum_{i} v_{i} x_{i o} \leq 0, \quad \forall k=1, \ldots, K_{I}$,

$y_{r o}, y_{r j} \geq 0 \quad \forall r, j$

$x_{i o}, x_{i j} \geq 0 \quad \forall i, j$.

\subsubsection{Fuzzy BSC-CCR model}

The mathematical formulation given by Eq. (11) under the condition that inputs and outputs coefficients are constants. However, there are many cases where we have data with uncertainty and one alternative to handle the uncertainty is to use fuzzy numbers as follows,

$\max { }_{u, v} z_{o}=\sum_{r} \tilde{u}_{r} y_{r_{o}}$,

subject to

$\sum_{i} \tilde{v}_{i} x_{i_{o}}=1$

$\sum_{\mathrm{r}} \tilde{u}_{r} y_{r j}-\sum_{i} \tilde{v}_{i} x_{i j} \leq 0 \quad \forall j$

$-\sum_{r \in o_{k}} \tilde{u}_{r} y_{r o}+L_{o_{k}} \sum_{r} \tilde{u}_{r} y_{r o} \leq 0 \quad \forall k=1, \ldots, K o$,

$\sum_{r \in o_{k}} \tilde{u}_{r} y_{r o}-U_{o_{k}} \sum_{r} \tilde{u}_{r} y_{r o} \leq 0 \quad \forall k=1, \ldots, K o$, 
$-\sum_{i \epsilon I_{k}} \tilde{v}_{i} x_{i o}+L_{I_{k}} \sum_{i} \tilde{v}_{i} x_{i o} \leq 0 \quad \forall k=1, \ldots, K_{I}$,

$\sum_{i \in I_{k}} \tilde{v}_{i} x_{i o}-U_{I_{k}} \sum_{i} \tilde{v}_{i} x_{i o} \leq 0 \quad \forall k=1, \ldots, K_{I}$,

$y_{r o}, y_{r j} \geq 0 \quad \forall r, j$

$x_{i o}, x_{i j} \geq 0 \quad \forall i, j$,

where $\tilde{v}_{i}=\left(v_{i}^{l}, v_{i}^{m}, v_{i}^{r}\right)$ and $\tilde{u}_{r}=\left(u_{r}^{l}, u_{r}^{m}, u_{r}^{r}\right)$ are triangular fuzzy numbers. Using Eq. (12) and Eq.

(7), we have the following,

$\max _{u, v} \sum_{r} u_{r}^{m} x_{r_{o}}$

subject to

$\sum_{i}\left(\alpha\left(\frac{v_{i}^{l}+v_{i}^{m}}{2}\right)+(1-\alpha)\left(\frac{v_{i}^{r}+v_{i}^{m}}{2}\right)\right) x_{i_{o}}=1$,

$\sum_{i}\left(\alpha\left(\frac{u_{r}^{l}+u_{r}^{m}}{2}\right)+(1-\alpha)\left(\frac{u_{r}^{r}+u_{r}^{m}}{2}\right)\right) y_{r_{j}} \leq \sum_{i}\left(\alpha\left(\frac{v_{i}^{l}+v_{i}^{m}}{2}\right)+(1-\alpha)\left(\frac{v_{i}^{r}+v_{i}^{m}}{2}\right)\right) x_{i_{j}}$,

$L_{o_{k}} \sum_{r}\left(\alpha\left(\frac{u_{r}^{l}+u_{r}^{m}}{2}\right)+(1-\alpha)\left(\frac{u_{r}^{r}+u_{r}^{m}}{2}\right)\right) y_{r_{o}} \leq \sum_{r \in o_{k}}\left(\alpha\left(\frac{u_{r}^{l}+u_{r}^{m}}{2}\right)+(1-\alpha)\left(\frac{u_{r}^{r}+u_{r}^{m}}{2}\right)\right) y_{r_{o}}$,

$\forall k=1, \ldots, K_{O}$,

$\sum_{r \in o_{k}}\left(\alpha\left(\frac{u_{r}^{l}+u_{r}^{m}}{2}\right)+(1-\alpha)\left(\frac{u_{r}^{r}+u_{r}^{m}}{2}\right)\right) y_{r_{o}} \leq U_{o_{k}} \sum_{r}\left(\alpha\left(\frac{u_{r}^{l}+u_{r}^{m}}{2}\right)+(1-\alpha)\left(\frac{u_{r}^{r}+u_{r}^{m}}{2}\right)\right) y_{r_{o}}$,

$\forall k=1, \ldots, K_{O}$,

$L_{I_{k}} \sum_{i}\left(\alpha\left(\frac{v_{i}^{l}+v_{i}^{m}}{2}\right)+(1-\alpha)\left(\frac{v_{i}^{r}+v_{i}^{m}}{2}\right)\right) x_{i_{o}} \leq \sum_{r \in I_{k}}\left(\alpha\left(\frac{v_{i}^{l}+v_{i}^{m}}{2}\right)+(1-\alpha)\left(\frac{v_{i}^{r}+v_{i}^{m}}{2}\right)\right) x_{i_{o}}$,

$\forall k=1, \ldots, K_{I}$,

$\sum_{i \in I_{k}}\left(\alpha\left(\frac{v_{i}^{l}+v_{i}^{m}}{2}\right)+(1-\alpha)\left(\frac{v_{i}^{r}+v_{i}^{m}}{2}\right)\right) x_{i_{o}} \leq U_{I_{k}} \sum_{i}\left(\alpha\left(\frac{v_{i}^{l}+v_{i}^{m}}{2}\right)+(1-\alpha)\left(\frac{v_{i}^{r}+v_{i}^{m}}{2}\right)\right) x_{i_{o}}$,

$y_{r o}, y_{r j} \geq 0 \quad \forall r, j$

$x_{i o}, x_{i j} \geq 0 \quad \forall i, j$.

$\alpha \in[0,1]$.

\section{Case study}

For many decades, the government managed banking system in Iran and there was not much competition among them. In 2000, the central bank of Iran decided to increase completion in banking sectors and issued permission for private sector to establish banks in this country. Bank Saman is believed to be the first private bank, which started its work in early years of 2000. There are different actions to increase the efficiency of banks in this country. Some of the most important ones are as follows,

- Respect to customers,

- Explicit information,

- Expansion of electronic banking,

- Competition among banks,

- Creation of occupations,

- Variety in profitability and introduction of new saving accounts.

In addition, the main reasons, which cause more development of private banks' activities are as follows,

- Bank rules changing compatible by private banks activities,

- Government altitude change to private banks from executive to super visional,

- Training bases of banking regime compatible by private banks activities,

- Elimination unequal conditions in competition among banks,

- Training and providing young human resources in scientific and academic centers compatible by private banking bases. 
In this paper, we focus our attention on the first private bank called Saman bank's activities including credit, monetary and financial services and engagement in different economical sectors with real and legal personalities. The following are some of the most important items,

- Increasing expectation about Bank Saman for undertaking main economic role in country,

- Activity intensification in different forms,

- Lack of occupation approach for bank personnel,

- Lack of pattern for branches site selection,

- Development of international and currency activities.

As we explained earlier, there are four major banks, which are candidates for a possible alliance with bank of Saman. Thus, we implement an integrated CCR and BSC method using fuzzy theory such that by using Delphi method, criteria considered by experts for making business alliance in electronic banking field are provided. The following summarizes the necessary steps and actions executed for the proposed model of this paper.

\subsection{First step: determination alternatives of a business alliance}

In this step, four commercial banks are presented for making a strategic alliance with Bank Saman $\left(A_{1}\right)$ in electronic banking field, which are Bank Parsian $\left(A_{2}\right)$, Bank Pasargad $\left(A_{3}\right)$, Bank Eghtesad Novin $\left(A_{4}\right)$ and Bank Sarmayeh $\left(A_{5}\right)$.

\subsection{Second step: determination criteria for selection of the best business alliance}

In this step, criteria for selection of the best business alliance are presented. In this research by using Delphi method, ten main criteria and fifty sub criteria are introduced, ten main criteria for evaluation and selection of business alliance are:

Resource equipment management $\left(C_{1}\right)$

Bank executive management $\left(C_{2}\right)$

Manpower $\left(C_{3}\right)$

Bank interior process $\left(C_{4}\right)$

Marketing activity $\left(C_{5}\right)$
Bank income and profitability $\left(C_{6}\right)$

Resource allocation management $\left(C_{7}\right)$

Branches efficiency $\left(C_{8}\right)$

E-banking $\left(C_{9}\right)$

Service $\left(C_{10}\right)$

The first main criterion, $C_{1}$, includes four sub criteria, which are cheap save to all saves, expensive save to all, saves growth and share of bank system. The second major criteria, $C_{2}$, incorporates five criteria, which are bank affair management, debt and property management, motivation, supervision and control and forecasting business activities. The third main factor, $C_{3}$, consists of five sub criteria, which are staff behavior to customers, staff professional knowledge, staff deposit per capita in bank, staff facility per capital in bank and the ratio of educated staff to all. The fourth main criterion, $C_{4}$, contains three sub-criteria, which are continuous process, the usage of advanced automated technology and having standard procedures. The fifth main item, $C_{5}$, incorporates five activities, which are long term relationship with customers, market separation, individual sales management, increase in sale by promotion plans, detecting other banks' special activities. The sixth criterion, $C_{6}$, includes four items, which are profit margin, revenue to total asset ratio, return of equity, the ratio of cost to revenue. The seventh criterion, $C_{7}$, includes the ratio of unpaid loans to the total amount of loans, the increase ratio of loans given to customers, the decrease ratio on unpaid loans, ownership ratio, the ratio of given loans to investment, the ratio of bank's loan from all loans. The eighth criterion, $C_{8}$, consists of four sub criteria, which are physical position of the bank and its competitive advantages, profit per capita of branches, deposit per capita of branches, the amount of loans given to customers per capita. The ninth criterion, $C_{9}$, has 12 sub-criteria, which are the number of 
transactions of each automated banking teller (ATM), the number of transactions of each position sells (POS), the ratio of debit cards to POSs, the ration of successful transaction to all transactions, the ratio of debit cards to ATMs, the average cash payment of each POS, the average amount of each transactions for each POS, the average amount of each transactions for each ATM and the average amount of transaction for each ATM. Finally, the last criterion, $C_{10}$, consists of service variation and innovation.

\subsection{Third step: how to select DMs and their relevant marks to criteria}

A total of 25 experts contributed their personal experiences, 20 of them are senior managers from the commercial banks in Iran and 5 experts are scholars who major in strategic management.

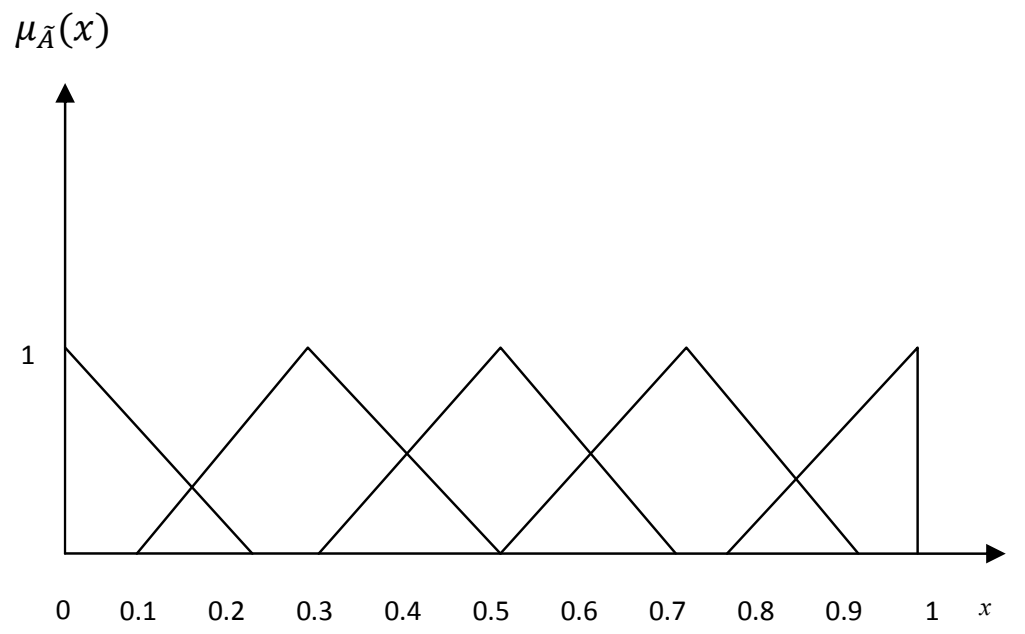

Fig. 3. Triangular fuzzy numbers between $[0,1]$.

Table 2 summarizes how to mark criteria and sub criteria by DMs based on Fig. 3 .

Table 2

Definitions of linguistic variables for the importance of each criteria and sub criteria

\begin{tabular}{ll} 
Very poor(VP) & $(0,0,0.2)$ \\
Poor(P) & $(0.1,0.3,0.5)$ \\
Medium(M) & $(0.3,0.5,0.7)$ \\
Good(G) & $(0.5,0.7,0.9)$ \\
Very Good(VG) & $(0.8,1,1)$ \\
\hline
\end{tabular}

\subsection{Fourth step: classification of criteria in DEA and BSC models}

In Table 3, the main criteria in four aspects of BSC have been presented for inputs and outputs of CCR model.

\section{Table 3}

Determination of main criteria in BSC and DEA models

\begin{tabular}{llllllll}
\hline Input & \multicolumn{7}{c}{ Output } \\
\hline Financial & $\begin{array}{l}\text { Learning } \\
\text { and maturity }\end{array}$ & $\begin{array}{l}\text { Interior } \\
\text { processes }\end{array}$ & customer & Financial & $\begin{array}{l}\text { Learning } \\
\text { and maturity }\end{array}$ & $\begin{array}{l}\text { Interior } \\
\text { processes }\end{array}$ & customer \\
\hline$C_{1}$ & $C_{2}, C_{3}$ & $C_{4}$ & $C_{5}$ & $C_{6}$ & $C_{7}$ & $C_{8}, C_{9}$ & $C_{10}$ \\
\hline
\end{tabular}




\subsection{Fifth step: grading alternatives upon criteria based on triangular fuzzy numbers}

In this step, sum of fuzzy numbers for all alternatives are calculated based on its criteria presented in Table 5. In this table, the number of ten criteria is calculated for every alternative based on the criteria of DEA model and by using Eq. (5). In addition, this method is used for completion of Table 6 and only difference is considering output criteria of DEA model in this Table.

\section{Table 5}

Triangular fuzzy numbers assigned to alternatives based on input criteria in DEA model

\begin{tabular}{lccccc}
\hline & $C_{1}$ & $C_{2}$ & $C_{3}$ & $C_{4}$ & $C_{5}$ \\
\hline$A_{1}$ & $(0,0.75,1)$ & $(0.18,0.58,0.82)$ & $(0,0.22,0.62)$ & $(0.22,0.47,0.72)$ & $(0.28,0.49,0.74)$ \\
$A_{2}$ & $(0,0.45,0.1)$ & $(0.13,0.33,0.5)$ & $(0,0.16,0.52)$ & $(0.08,0.36,0.62)$ & $(0.1,0.37,0.62)$ \\
$A_{3}$ & $(0,0.3,1)$ & $(0,0.2,0.7)$ & $(0,0.15,0.5)$ & $(0.04,0.31,0.66)$ & $(0,0.22,0.52)$ \\
$A_{4}$ & $(0,0.5,1)$ & $(0.01,0.23,0.43)$ & $(0,0.2,0.7)$ & $(0.01,0.28,0.58)$ & $(0.08,0.34,0.69)$ \\
$A_{5}$ & $(0,0.55,1)$ & $(0.04,0.24,0.48)$ & $(0,0.2,0.7)$ & $(0.02,0.21,0.5)$ & $(0.08,0.45,0.76)$ \\
\hline \multicolumn{7}{c}{} & $\mathrm{C} 6$ & $\mathrm{C} 7$ & $\mathrm{C} 8$ & $\mathrm{C} 9$ & $\mathrm{C} 10$ \\
\hline$A 1$ & $(0,0.1,0.2)$ & $(0,0.7,1)$ & $(0.3,0.71,1)$ & $(0,0.76,1)$ & $(0.38,0.54,0.7)$ \\
$A 2$ & $(0,0.7,1)$ & $(0,0.5,1)$ & $(0.32,0.79,1)$ & $(0,0.82,1)$ & $(0.38,0.54,0.7)$ \\
$A 3$ & $(0,0.7,1)$ & $(0,0.89,0.9)$ & $(0.74,0.89,1)$ & $(0,0.9,1)$ & $(0.74,0.86,0.98)$ \\
$A 4$ & $(0.1,0.6,0.9)$ & $(0,0.8,1)$ & $(0.34,0.8,1)$ & $(0,0.69,1)$ & $(0.41,0.61,0.78)$ \\
\hline
\end{tabular}

\section{Sixth step: solving the model and selection of optimum business alliance 5.6}

Using Eq. (13) and the fuzzy numbers given in Table 5 yields the optimal solution given in Table 6 .

\section{Table 6}

The results of the optimal solution for different values of lower and upper bounds

\begin{tabular}{lllllllllll}
\hline Alternative & $\alpha$ & $L_{O}, L_{I}$ & $U_{O}, U_{I}$ & Efficiency & Rank & $\alpha$ & $L_{O}, L_{I}$ & $U_{O}, U_{I}$ & Efficiency & Rank \\
\hline$A_{1}$ & 0.1 & 0.1 & 0.9 & 0.473 & 5 & 0.1 & 0.2 & 0.8 & 0.35 & 5 \\
$A_{2}$ & 0.1 & 0.1 & 0.9 & 0.819 & 3 & 0.1 & 0.2 & 0.8 & 0.73 & 2 \\
$A_{3}$ & 0.1 & 0.1 & 0.9 & 1 & 1 & 0.1 & 0.2 & 0.8 & 0.99 & 1 \\
$A_{4}$ & 0.1 & 0.1 & 0.9 & 0.797 & 4 & 0.1 & 0.2 & 0.8 & 0.64 & 3 \\
$A_{5}$ & 0.1 & 0.1 & 0.9 & 0.825 & 2 & 0.1 & 0.2 & 0.8 & 0.63 & 4 \\
\hline
\end{tabular}

We first chose 0.1 for $L_{O}, L_{I}$ and 0.9 for $U_{O}, U_{I}$ and second we chose 0.2 for $L_{O}, L_{I}$ and 0.8 for $U_{O}, U_{I}$. Columns five and six of Table 6 demonstrate the results of the ranking for the first set of data and the last two columns show the ranking using the second data. As we can see, the third alternative, Pasargad bank, comes first in terms of ranking for both set of data and Saman bank comes the weakest in terms of the ranking in both cases. Our investigation also confirm the results we obtained since bank of Pasargad uses better resource allocation, electronic services and electronic banking systems compared with bank of Saman.

\section{Conclusion}

In this paper, we have presented a BSC-DEA based model to indentify strengths, weaknesses, opportunities and threats of a financial firm from banking sector. The proposed model of this paper assumed there are various uncertainties associated with all input/output parameters and used fuzzy numbers to handle the uncertainties. We also considered a real-world case study of banking industry where four major banks were possible candidates of a partnership and implemented the proposed model of this paper for this case study. The results of this study showed that the relative efficiencies of different banks, which helped us detect the most efficient bank for possible alliance. The results also indicated that the case study of this paper, bank of Saman, performed poorly compared with other alliance candidates in terms of using the recent advances of high technology. 


\section{References}

Asosheh, A., Nalchigar, S., \& Jamporazmey, M.(2010). Information technology project evaluation: An integrated data envelopment analysis and balanced scorecard approach. Expert Systems with Applications, 37, 5931-5938.

Bhagwat, R., \& Sharma, M. K.(2007). Performance measurement of supply chain management: A balanced scorecard approach. Computers and Industrial Engineering, 53, 43-62.

Bierly III P.E., \& Gallagher S. (2007). Explaining alliance partner selection: Fit, trust and strategic expediency. Long Range Planning, 40, 134-153.

Bremser, W.G., \& Chung, Q. B. (2005). A framework for performance measurement in the ebusiness environment. Electronic Commerce Research and Applications, 4, 395-412.

Brendel, L. H. (1951). Where to find and how to choose your industrial distributors. Sales Management, 15(September), 128-132.

Campbell, D., Datar, S., Kulp, S.C., \& Narayanan, V.G. (2002). Using the balanced scorecard as a control system for monitoring and revising corporate strategy. Harvard NOM Working paper, 235 .

Chand, D., Hachey, G., Hunton, J., Owhoso, V., \& Vasudevan, S. (2005). A balanced scorecard based framework for assessing the strategic impacts of ERP systems. Computers in Industry, 56, $558-572$.

Charnes, A., Cooper, W.W., Rhodes, E.(1978). Measuring the efficiency of decision making units. European Journal of the Operational Research, 2, 429-444.

Doherty, A.M.(2009). Market and partner selection process in international retail franchising. Journal of Business Research, 62, 528-534.

Dong, L., \& Glaister K.W.(2006). Motives and partner selection criteria in international strategic alliances: Perspectives of Chinese firms. International Business Review, 15, 577-600.

Dubois, D., \& Prade, H. (1980). Fuzzy Sets and Systems: Theory and Applications. New York: Academic Press Inc.

Eden, L. (2007). Friends, acquaintances, or strangers Partner selection in R\&D Alliances. Texas A\&M University, Bush School.

Eilat, H., Golany, B., \& Shtub, A. (2008). R\&D project evaluation: An integrated DEA and balanced scorecard approach. Omega, 36, 895-912.

Hacklin, F., Marxt, C., \& Fahrni F. (2006). Strategic venture partner selection for collaborative innovation in production systems: A decision support system-based approach. International Journal of Production Economics, 104, 100-112.

Hasan, H., \& Tibbits, H. (2000). Strategic management of electronic commerce: An adaption of the balanced scorecard. Internet Research, 10, 439-450.

Holmberg, S.R., \& Cummings, J.L.(2009). Building successful strategic alliances. Long Range Planning, 42, 164-193.

Ittner, C.D., Larcker, D.F., \& Randall, T. (2003). Performance implications of strategic performance measurement in financial services firms. Accounting, Organizations and Society, 28, 715-741.

Jarimo, T. (2006). Partner selection and utility sharing in collaborative networks. Licentiate's Thesis, Helsinki University of Technology, Department of Engineering Physics and Mathematics.

Jiménez, M., Arenas, M., Bilbao, A., \& Rodríguez, M.V.(2007). Linear programming with fuzzy parameters: An interactive method resolution. European Journal of Operational Research, 177, 1599-1609.

Kaplan, R.S., \& Norton, D.P.(1992). The balanced scorecard: measures that drive performance. Harvard Business Review, 70, 71-79.

Kaufmann, A., \& Gupta, M. (1991). Introduction to Fuzzy Arithmetic: Theory and Applications. New York: Van Nostrand Reinhold.

Quezada, L.E., Cordova, F.M., Palominos, P., Godoy, K., \& Ross, J. (2009). Method for identifying strategic objectives in strategy maps. International Journal of Production Economics, 122, 492500 . 
Maltz, A. C., Shenhar, A. J., \& Reilly, R. R. (2003). Beyond the balanced scorecard: Refining the search for organizational success measures. Long Range Planning, 36, 187-204.

Mikhailov, L. (2002). Fuzzy analytical approach to partner selection in formation of virtual enterprises. Omega (The International Journal of Management Science), 30, 393-401.

Overby, M.L.(2005). Partner selection criteria in strategic alliances: when to ally with weak Partners. Denmark: Mobiconomy project at Copenhagen business school. DRUID working paper No.05-07. ISBN 87-7873-171-2

Pegram, R.(1965). Selecting and evaluating distributors. New York: National Industrial Conference Board.

Rickards, R. C. (2007). BSC and benchmark development for an e-commerce SME. Benchmarking: An International Journal, 14, 222-250.

Tsao, C.T. (2009). The revised algorithms of fuzzy variance and an application to portfolio selection. Soft Computing - A Fusion of Foundations, Methodologies and Applications, 14(4), 329-337.

Wong-On-Wing, B., Guo, L., Li, W., \& Yang, D. (2007). Reducing conflict in balanced scorecard evaluations. Accounting, Organizations and Society, 32, 363-377.

Wu, Y.W., Shih, H.A., \& Chan H.C.(2009). The analytic network process for partner selection criteria in strategic alliances. Expert Systems with Applications, 36, 4646-4653.

Yang, D.H., Kim, S., Nam, C., \& Min, J.W.(2007). Developing a decision model for business process outsourcing. Computers and Operation Research, 34, 3769-3778.

Zadeh, L. A. (1965). Fuzzy sets. Information Control, 8, 338-353. 